\title{
RESEARCH
}

\section{Inhibition of Notch signaling attenuates pituitary adenoma growth in Nude mice}

\author{
Lautaro Zubeldía-Brenner1, Catalina De Winne1, Sofía Perrone², Santiago A Rodríguez-Seguí3,4, Christophe Willems5, \\ Ana María Ornstein ${ }^{1}$, Isabel Lacau-Mengido, Hugo Vankelecom5, Carolina Cristina ${ }^{2 *}$ and Damasia Becu-Villalobos ${ }^{1 *}$ \\ IInstituto de Biología y Medicina Experimental, IBYME-CONICET, Buenos Aires, Argentina \\ ${ }^{2}$ Centro de Investigaciones y Transferencia del Noroeste de la Provincia de Buenos Aires, CITNOBA (UNNOBA-CONICET), Universidad Nacional del \\ Noroeste de la Provincia de Buenos Aires, Buenos Aires, Argentina \\ ${ }^{3}$ Departamento de Fisiología y Biología Molecular y Celular, Universidad de Buenos Aires, Facultad de Ciencias Exactas y Naturales, Buenos \\ Aires, Argentina \\ ${ }^{4}$ CONICET-Universidad de Buenos Aires, Instituto de Fisiología, Biología Molecular y Neurociencias (IFIBYNE), Buenos Aires, Argentina \\ 5Department of Development and Regeneration, Cluster Stem Cell and Developmental Biology, Unit of Stem Cell Research, KU Leuven (University of \\ Leuven), Leuven, Belgium
}

Correspondence should be addressed to D Becu-Villalobos: dbecu@dna.uba.ar

*(C Cristina and D Becu-Villalobos contributed equally)

\begin{abstract}
Preclinical and clinical studies support that Notch signaling may play an important oncogenic role in cancer, but there is scarce information for pituitary tumors. We therefore undertook a functional study to evaluate Notch participation in pituitary adenoma growth. Tumors generated in Nude mice by subcutaneous GH3 somatolactotrope cell injection were treated in vivo with DAPT, a $\gamma$-secretase inhibitor, thus inactivating Notch signaling. This treatment led to pituitary tumor reduction, lower prolactin and GH tumor content and a decrease in angiogenesis. Furthermore, in silico transcriptomic and epigenomic analyses uncovered several tumor suppressor genes related to Notch signaling in pituitary tissue, namely Btg2, Nr4a1, Men1, Zfp36 and Cnot1. Gene evaluation suggested that $\mathrm{Btg} 2, \mathrm{Nr} 4 a 1$ and $\mathrm{Cnot1}$ may be possible players in GH3 xenograft growth. Btg2 mRNA expression was lower in GH3 tumors compared to the parental line, and DAPT increased its expression levels in the tumor in parallel with the inhibition of its volume. Cnot1 mRNA levels were also increased in the pituitary xenografts by DAPT treatment. And the Nr4a1 gene was lower in tumors compared to the parental line, though not modified by DAPT. Finally, because DAPT in vivo may also be acting on tumor microenvironment, we determined the direct effect of DAPT on GH3 cells in vitro. We found that DAPT decreases the proliferative, secretory and migration potential of $\mathrm{GH} 3$ cells. These results position selective interruption of Notch signaling as a potential therapeutic tool in adjuvant treatments for aggressive or resistant pituitary tumors.
\end{abstract}

\section{Introduction}

Pituitary adenomas are mostly benign intracranial tumors, which do not metastasize but may recur after surgical removal, compress nearby structures or produce considerable morbidity related to hormonal dysfunction. A subset of these tumors may be aggressive, atypical or recurrent, and presently, there is a paucity of molecular https://erc.bioscientifica.com https://doi.org/10.1530/ERC-18-0337
(C) 2019 Society for Endocrinology Published by Bioscientifica Ltd. Printed in Great Britain
Key Words

$\checkmark$ DAPT

- pituitary

- angiogenesis

- prolactin

- $\mathrm{GH}$ 
markers that could improve diagnosis, treatment and prognosis. Stem-like cell activation of different components of the Notch pathway have been consistently detected in pituitary tumors (Mertens et al. 2015) suggesting potential therapeutic benefit for targeting Notch in tumoral pituitaries. Nevertheless, functional studies linking the Notch pathway with pituitary tumorigenesis are lacking.

Notch signaling regulates numerous cellular processes, including stem cell maintenance, proliferation, cellular differentiation and apoptosis (Artavanis-Tsakonas \& Muskavitch 2010). It maintains precursor cells by balancing cellular proliferation, cell fate decisions and differentiation in several tissues such as brain, muscle, intestine and the hematopoietic system. It is therefore not surprising that Notch pathway dysfunction is implicated in the pathogenesis of adult human disease, including cancer (Ranganathan et al. 2011).

The mammalian Notch receptor family consists of four type 1 transmembrane receptors (termed $\mathrm{NOTCH}$ 1-4), which are synthesized as precursor forms and cleaved by a furin-like convertase to generate the mature receptor, composed of two subunits: an extracelluar and an intracelluar domain (NICD) held together by noncovalent interactions. Notch signaling is initiated by cell-to-cell contact of the receptor with the neighboringcell Notch ligands Jagged1 and 2 (JAG1 and JAG2) and Delta-like 1,3 and 4 (DLL1,3,4). Ligand binding initiates a series of cleavages and a final cleavage mediated by the $\gamma$-secretase complex, which releases NICD from the plasma membrane so that it can translocate into the nucleus where it recruits a transcriptional activation complex activating and repressing genes. Classical target genes are the transcriptional factors of the Hairy Enhancer of Split (HES) family (HES 1,5,6, and 7), the Hairy-Related Transcription factor family (HRT1,2 and 5; also known as HEY), Notch receptors, Notch ligands, cyclin D1 and MYC (Bray 2006, Gordon et al. 2008), among others.

Substantial evidence derived from preclinical and clinical studies support that Notch signaling may play an important oncogenic role in several types of cancer. In particular, most patients with $\mathrm{T}$ cell acute lymphoblastic leukaemia (T-ALL) harbor activating mutations in the NOTCH1 gene, which result in ligand-independent proteolytic cleavage of the receptor and increased stability of the NICD (Ellisen et al. 1991). This leads to constitutive activation of the Notch pathway and neoplastic transformation of T cells. Nevertheless, in solid tumors, there is little evidence for genetic alterations in Notch genes, even though Notch signaling seems to be crucial in the generation and progression of breast, colon, pancreas Printed in Great Britain and prostate cancer (Radtke \& Raj 2003). Intriguingly, Notch signaling may also have a tumor suppressor role as it was described in mouse keratinocytes, pancreatic and hepatocellular carcinoma (Koch \& Radtke 2010, Ranganathan et al. 2011).

The versatility and pleiotropic effects, which result from aberrant Notch activity may be interpreted based on contextual and developmental cues. Moreover, each tissue and even every cellular component within a tissue express different proportions of Notch paralogs and target genes, which may ultimately determine cell fate during Notch dysfunction. Activity and outcome of increased Notch signaling may therefore depend on the specific paralog involved as found in medulloblastoma tumors (Castro et al. 2003) and in breast (Harrison et al. 2010) and pancreatic carcinomas (Avila \& Kissil 2013). Complexity is increased when target genes are considered, leading to the concept that Notch activity outcome depends on cellular context.

In the search for targets for pituitary adenoma combinatorial treatment, elucidation of relevant Notch signaling components within each adenoma type would be highly valuable. Knowledge on the participation of the Notch system in pituitary tumor generation and progression is scarce. In general, links between pituitary adenomas and Notch have been revealed by the description of expression levels of Notch pathway elements, but to our knowledge, no functional study has been performed so far. Notch 3 was increased in prolactinomas and non-functioning adenomas (Moreno et al. 2005, Evans et al. 2008, Miao et al. 2012, Lu et al. 2013) and decreased in somatotropinomas (Lu et al. 2013). Furthermore, HES1 expression was decreased in prolactinomas and nonfunctioning adenomas (Evans et al. 2008), and levels of Jagged1 were increased (Lu et al. 2013). Importantly, in pituitary adenomas, the side population with stem cell characteristics showed increased levels of HES1, JAGGED1 as well and NOTCH 1,2 and 4 (Mertens et al. 2015). Furthermore, pituitary adenoma-derived stemlike cells express higher levels of NOTCH4, JAG2 and DLL1 and are more resistant to chemotherapeutics than their differentiated daughter cells (Xu et al. 2009).

We recently found that all four Notch receptors are expressed in the pituitary gland and also demonstrated enhanced gene expression of the Notch ligands Jag1 and Dll1, and the target gene Hey1, as well as activated Notch2 intracellular domain N2ICD in the somatolactotrope cell line GH3 compared to normal rat pituitaries (Perrone et al. 2017). Furthermore, in prolactinomas harbored by 
lacDrd2KO female mice an activated Notch signaling pathway was found (Perrone et al. 2017). Therefore, in the present study, we undertook a functional approach to evaluate Notch participation in pituitary adenoma growth. GH3 somatolactotrope tumors generated in Nude mice were treated with a $\gamma$-secretase inhibitor, $\mathrm{N}-[\mathrm{N}-(3,5-$ difluorophenacetyl)- L-alanyl]-S-phenylglycine t-butyl ester (DAPT), thus inactivating Notch signaling. Tumor development, Notch signaling component expression and angiogenic and proliferative markers were assessed. Furthermore, because regulation of Notch signaling pathways is specific for each tumor type, we undertook a bioinformatic approach based on a combined epigenomic and transcriptomic analysis to identify Notch target genes with a potential role in tumor suppression, which may be relevant to pituitary tumors. We next determined their expression in treated and untreated GH3 xenografts. Finally, because DAPT in vivo may be acting not only on pituitary tumor cells, but also on endothelial cells or modifying the extracellular matrix of the tumor, we determined the direct effect of DAPT on GH3 cells in vitro. Our results demonstrate that inhibiting Notch signaling in vivo leads to pituitary tumor reduction and a decrease in tumor angiogenesis. In addition, DAPT acts directly on GH3 cells decreasing their proliferation, secretory and migration potential. These results position selective interruption of Notch signaling as a potential therapeutic tool in the search for adjuvant treatments in aggressive or resistant pituitary tumors.

\section{Materials and methods}

\section{Cell line and culture conditions}

GH3 rat somato-prolactinoma cell line (ATCC, CCL-82.1) was cultured in adhesion as reported (Vela et al. 2007) in DMEM/F12K medium, supplemented by $2.5 \%(\mathrm{v} / \mathrm{v})$ fetal bovine serum, $15 \%(\mathrm{v} / \mathrm{v})$ horse serum, $1 \%$ glutamine and $1 \%(\mathrm{w} / \mathrm{v})$ penicillin/streptomycin and fungizone, $\mathrm{pH} 7.3$ and maintained at $37^{\circ} \mathrm{C}$ and $5 \% \mathrm{CO}_{2}$. After incubation in serum-free medium for $18-24 \mathrm{~h}$ cells were treated with DAPT 1, 5 and $10 \mu \mathrm{M}$ (Calbiochem Cat No: 565770) or vehicle. Medium was refreshed every $24 \mathrm{~h}$ with the appropriate stimuli. Aliquots of supernatant were collected for $\mathrm{GH}$ and prolactin measurements at 24 and $48 \mathrm{~h}$. To analyze gene and protein expression, cells were detached and dissociated using trypsin $(0.05 \%)$ with EDTA $(0.02 \%$; Life Technologies).

For GH3 sc injections in Nude mice, GH3 cells were cultured and detached as indicated, and trypsin was inactivated with excess $(20 \mathrm{~mL})$ F12K medium (supplemented with 15\% (v/v) horse serum, 2.5\% (v/v) bovine fetal serum). Cells were centrifuged for $10 \mathrm{~min}$ at $950 \mathrm{rpm}, 23^{\circ} \mathrm{C}$, the pellet resuspended in $1 \mathrm{~mL}$ PBS or $\mathrm{F} 12 \mathrm{~K}$ medium and cells were counted.

\section{Experiments with athymic Nude mice}

Nude mice BALB/C NU/NU were housed at the Animal House Facility of the Instituto de Biología y Medicina Experimental. Experimental tumors were induced by sc injection of $700,000 \mathrm{GH} 3$ cells suspended in $100 \mu \mathrm{L}$ PBS in one flank of adult female Nude mice. DAPT treatment was started when the tumor volume had reached about $70 \mathrm{~mm}^{3}$ in size (approximately 21 days after GH3 injection). DAPT was dissolved in $0.5 \mu \mathrm{M}$ DMSO-PBS, and $8 \mathrm{mg} / \mathrm{kg}$ BW per mouse was administered i.p., thrice a week. Vehicle-treated animals served as controls. The tumor volume was regularly determined with a caliper until the animals were killed after 3 weeks of treatment. Tumors were excised, weighed and frozen at $-70^{\circ} \mathrm{C}$ for mRNA and protein studies and a portion was embedded in paraffin for immunohistochemical studies.

All experimental procedures were carried according to guidelines of the Institutional Animal Care and Use Committee of the Instituto de Biología y Medicina Experimental, Buenos Aires (in accordance with the Animal Welfare Assurance for the Instituto de Biología y Medicina Experimental, Office of Laboratory Animal Welfare, NIH, A\#5072-01). Study \#07/2016 was approved by IBYME IACUC.

\section{RNA extraction and cDNA synthesis}

Xenotransplant tissue or GH3 cells cultured in vitro were processed for recovery of total RNA using TRIzol reagent (Invitrogen). Reverse transcription was performed as previously described (Perrone et al. 2017).

\section{Real-time PCR}

Measurements were performed as previously described (Garcia-Tornadu et al. 2009, Perrone et al. 2017). Sense and antisense oligonucleotide primers were designed on the basis of the published cDNA or by the use of PrimerBlast (http://www.ncbi.nlm.nih.gov/tools/primerblast/). Oligonucleotides were obtained from Invitrogen. The sequences are described in Supplementary Table 1 (see section on supplementary data given at the end of this article). 


\section{Western blot}

Xenotransplant and cell lysates were homogenized in a motor microtissue mixer in $80-300 \mu \mathrm{L}$ of lysis buffer (50 mM HEPES (pH 7.4), $140 \mathrm{mM} \mathrm{NaCl}, 10 \%$ (v/v) glycerol, $1 \mathrm{mM}$ EDTA, $1 \mathrm{mM}$ sodium orthovanadate, $10 \mathrm{mM}$ sodium pyrophosphate, $100 \mathrm{mM}$ sodium fluoride, 1\% Triton $\mathrm{X}-100$ ), and $1 \mathrm{mM}$ phenymethylsulfonyflouride and protease cocktail inhibitor (Roche Diagnostic) were added to the buffer just before use. The homogenate was then centrifuged at $12,000 \mathrm{rpm}$ for $30 \mathrm{~min}$ at $4^{\circ} \mathrm{C}$. An aliquot of the supernatant was taken to quantify proteins by the Qubit Quant-it protein assay kit (Invitrogen).

Thirty to forty micrograms of proteins in $20 \mu \mathrm{L}$ of homogenization buffer were mixed with $5 \mu \mathrm{L}$ of $5 \times$ sample buffer (312 mM Tris-HCl, 10\% SDS, 25\% glycerol, $0.002 \%$ bromophenol blue and 1\% Beta-mercaptoethanol, $\mathrm{pH}$ 6.8). Samples were heated $5 \mathrm{~min}$ at $95^{\circ} \mathrm{C}$ and separated by $10 \%$ SDS-PAGE and electrotransferred to nitrocellulose membranes (G\&E, Little Chalfont, UK). After blocking with 3\% nonfat dry milk solution in phosphate saline buffer - Tween (PBST) (10 mM sodium phosphate, $2 \mathrm{mM}$ potassium phosphate $\mathrm{pH} 7.4,140 \mathrm{mM} \mathrm{NaCl}, 3 \mathrm{mM} \mathrm{KCl}$, and $0.1 \%$ Tween 20) blots were incubated overnight at $4^{\circ} \mathrm{C}$ with primary antibodies. Antibodies used were rabbit polyclonal anti-Notch 1 (1/1000, EMD-Millipore, Cat \#07-1232), anti-Notch2 (1:1000, Merck Millipore): antiHes1 (1:1000, EMD-Millipore, Cat. \#AB5702).

Membranes were washed with PBST and incubated with the corresponding horse radish peroxidase (HRP)conjugated secondary antibody, and protein bands were detected in a G:box chemi HR16 (Syngene, Frederick, MD, USA). The monoclonal beta-Tubulin (1:7000, Sigma-Aldrich, Cat \#T0198) was used to validate equal amount of protein loaded and transferred. For repeated immunoblotting, membranes were incubated in stripping buffer $(62.5 \mathrm{mM}$ Tris, $2 \%$ sodium dodecyl sulfate and $100 \mathrm{~mm}$ mercaptoethanol, $\mathrm{pH}$ 6.7) for $40 \mathrm{~min}$ at $55^{\circ} \mathrm{C}$ and reprobed. Band intensities were quantified using ImageJ software (National Institutes of Health, Bethesda, MD, USA).

NOTCH1-2 expression levels were evaluated by the semi-quantification of two bands, the active intracellular domain (NICD) of $80 \mathrm{kDa}$ and the membrane domain plus the NICD of the receptor of $110 \mathrm{kDa}$.

\section{Prolactin and GH RIAs}

\section{Serum}

Aliquots $(10 \mu \mathrm{L})$ of serum obtained from Nude mice were used to assay serum prolactin and GH by RIA.

\section{Tissue}

Xenotransplanted GH3 tumoral samples (1-5 mg) were homogenized in ice-cold PBS and centrifuged at $3000 \mathrm{rpm}$ for $5 \mathrm{~min}$. Supernatant protein contents were measured with the QUBIT Fluorometer and the QUANT-IT protein Assay Kit (Invitrogen). Aliquots of equal quantity of protein were used to assay GH and prolactin content.

In vitro supernatants from cultured GH3 cells, $10 \mu \mathrm{L}$ diluted 1/20-1/40, were kept at $-20^{\circ} \mathrm{C}$ for $\mathrm{GH}$ and prolactin RIA assays.

RIA assays were performed using kits provided by the National Institute of Diabetes and Digestive and Kidney Diseases (NIDDK; Dr. A.F. Parlow, National Hormone and Pituitary Program (NHPP), Torrance, CA). Results are expressed as $\mathrm{ng} / \mathrm{mL}$ for in vitro studies and serum, and $\mathrm{ng} / \mu \mathrm{g}$ protein for xenograft content, in terms of rat prolactin standard RP3 and GH standard AFP-10783B. Intra- and inter-assay coefficients of variation were 7.2 and $12.8 \%$ and 8.4 and $13.2 \%$, for prolactin and $\mathrm{GH}$, respectively. Sensitivity threshold was 0.02 and $0.04 \mathrm{ng}$ for prolactin and $\mathrm{GH}$, respectively.

\section{Quantification of cell proliferation}

\section{MTS proliferation assay}

Proliferation of GH3 cells was colorimetrically determined at $490 \mathrm{~nm}$ using a commercial proliferation assay kit CellTiter 96 (AQueous Non-Radioactive Cell Proliferation Assay, Promega Corp.) following the manufacturer's instructions. Cell cultures were repeated four times and each had duplicate samples.

\section{Cell motility assay}

Cell motility was evaluated using the 'scratch assay'. After reaching 90\% confluence, GH3 cells were serum-starved for $24 \mathrm{~h}$ and then treated with mitomycin C $(10 \mu \mathrm{g} / \mathrm{mL}$; Calbiochem 475820) to inhibit cell proliferation. A straight scratch was created, and cells were further kept in DMEM/F12K (2\% horse serum, 1\% fetal bovine serum), together with DAPT ( 5 and $10 \mu \mathrm{M}$ ) or vehicle. Medium was changed every $24 \mathrm{~h}$. The migration of cells into the scratch was evaluated by light microscopy, and live pictures were taken with an Olympus CKX 41 microscope at different time points. The open area was calculated using the image processing and analysis software ImageJ http://rsbweb. nih.gov/ij/. 
Tumor microvessel density, vascular area and vessel size assessment

\section{Immunohistochemistry}

Xenotransplants were deparaffinized and dehydrated in graded ethanols. A microwave pre-treatment for antigen retrieval was performed in $10 \mathrm{mM}$ sodium citrate buffer, $\mathrm{pH}$ 6. Endogenous peroxidase activity and nonspecific binding sites were blocked. Primary antibody (goat polyclonal antibody PECAM for CD31 endothelial cell detection (1:200, sc-1506 Santa Cruz Biotechnologies Inc.) or rabbit polyclonal SMA antibody (1:200; $\alpha$-SMA ab15734; Abcam) for vessel mural cell detection) was incubated overnight at $4^{\circ} \mathrm{C}$. After incubation with biotinconjugated secondary antibody for $1 \mathrm{~h}$, the reaction was developed using an avidin-biotin kit coupled to peroxidase (Vector Laboratories, Burlingame, CA, USA) and diaminobenzidine as a chromogen substrate. Samples were counterstained with hematoxylin and mounted with permanent mounting medium. Each immunohistochemical run included negative controls replacing the primary antibody with PBS. As a measure of angiogenesis, we determined the microvascular density (MVD) by counting the number of CD31+ or aSMA+ vessels per square millimetre, the vascular area determined by the cumulative area of the tumor occupied by $\mathrm{CD} 31^{+}$or aSMA+ vessels and expressed as \% vessel area/total area and the average vessel size. Images of randomly selected fields were recorded using $40 \times$ or 100× objective, using a Zeiss Axiostar Plus microscope and a Canon PowerShot G6 digital camera. Three slides per tumor (4 tumors per group) were analyzed and at least five images per slide at $400 \times$ of total magnification were counted by the image processing and analysis software: Image J, http://rsbweb. nih.gov/ij/.

\section{Bioinformatic analysis}

Publicly available raw RNA-seq datasets were obtained from the Sequence Read Archive (SRA) database as listed in Supplementary Table 2. Human normal pituitary datasets used for the analyses described in this manuscript were obtained from dbGaP at http://www.ncbi.nlm.nih. gov/gap through dbGaP accession number phs000424. v6.p1. Raw read sequence alignment and gene expression quantification was performed with the Tuxedo suite (Langmead et al. 2009, Trapnell et al. 2009, 2012). In brief, raw reads were first aligned to the human genome (hg19 version) using TopHat v2.0.12 (Trapnell et al. 2009) with default parameters, and Cufflinks (Trapnell et al. 2012) was used with default settings to quantify the expression levels as fragments per kilobase of exon per million fragments mapped (FPKM). Further analysis included normalization of transcript levels and differential expression analysis using Cuffnorm and Cuffdiff tools (Trapnell et al. 2012).

Publicly available raw ChIP-seq datasets were obtained from the Sequence Read Archive (SRA) database as listed in Supplementary Table 3, and aligned and processed as follows to infer putative Notch1-bound regulatory regions in pituitary GC cells. Sequence reads were aligned to the rat genome (version rn4) using Bowtie 1.1.1 (Langmead et al. 2009). Only sequences uniquely aligned with $\leq 1$ mismatch were retained. Post-alignment processing of sequence reads included in silico extension and signal normalization based on the number of million mapped reads. Reads were extended to a final length equal to MACS fragment size estimation (Zhang et al. 2008), and only unique reads were retained. For signal normalization, the number of reads mapping to each base in the genome was counted using the genomeCoverageBed command from BedTools(Quinlan \& Hall 2010). Processed files were visualized in the UCSC genome browser (Kent et al. 2002). ChIP-seq enrichment sites were detected with MACS v1.4.0beta (Zhang et al. 2008) using default parameters and a $P$ value of 1 e-5. A control dataset derived by sequencing input DNA samples was used to define a background model.

Next, active regulatory regions in GC cells were defined as H3K27ac-enriched genomic sites that overlapped with H3K4me1 signal in rat GC cells. To infer putative Notch1 binding, we lifted over the Notch1 peaks as published by the group of Dr Pear (Zhang et al. 2008) to the rat genome (rn4) and searched for overlap among these sites and the active regulatory regions profiled in GC cells. For gene ontology analysis, the putatively Notch1-bound active regulatory regions in GC cells were lifted over to the mouse (mm9) genome, regions were associated to genes and gene ontology analysis was performed using GREAT with default settings. To gain further insights into the tissue specificity of the regulatory regions of interest for this work, we also downloaded, re-aligned and analyzed a Pit1 ChIP-seq dataset profiled in GC cells.

Combination of in silico transcriptomic and epigenomic analyses allowed us to choose several tumor suppressors associated with enhancers potentially bound by Notch1 (and thus putative downstream targets of Notch signaling) to be evaluated in our experiment, namely Btg2, Nr4a1, Men1, Zfp36 and Cnot1. 


\section{Statistical analysis}

Results are expressed as means \pm s.E.M. The differences between means were analyzed by the unpaired Student's $t$-test in the case of only two groups. Two-way ANOVA with repeated-measures design was used to analyze tumor volume in vivo, prolactin and GH secretion in vitro, protein and gene expression in vitro, motility and proliferation assays, for the effects of drug and time. Post hoc Tukey's test was employed when necessary. Parametric or nonparametric comparisons were used as dictated by data distribution. $P<0.05$ was considered significant.

\section{Results}

\section{Notch signaling inhibition decreased xenograft tumor growth and prolactin and GH content in GH3-inoculated Nude mice}

Mice s.c. inoculated with 700,000 GH3 cells developed visible tumors 21 days after inoculation (Volume $\left.61.0 \pm 7.1 \mathrm{~mm}^{3}\right)$; at this point, i.p. DAPT treatment was started (day 0). Xenograft volumes in DAPT-treated mice were consistently smaller at all time points, and statistical significance was achieved beginning on day 16 after the initiation of treatment (Fig. 1A). Body weight remained unaltered during treatment (Fig. 1B). Average tumor volume was $42 \%$ lower in DAPT-treated mice at killing (Fig. 1A), and prolactin and GH tumor content and serum prolactin levels were significantly decreased in the DAPT group at the end of the treatment period (Fig. 1C).

\section{DAPT treatment decreased Notch 2 intracellular domain, the target protein HES1 and target gene Hey2}

By Western blot, we identified NOTCH 1 and 2 active intracellular domain (NICD $80 \mathrm{kDa}$ ) and the membrane domain (110 kDa). N2ICD significantly decreased after inhibition of $\gamma$-secretase by DAPT (Fig. 2A), while membrane domain levels were not modified. Furthermore, DAPT treatment decreased HES1, a Notch target protein (Fig. 2B). These results indicate that i.p. DAPT effectively reduced Notch activation and signaling in xenografts.

Messenger RNA levels of Notch2 receptor, Notch ligands (Jagged 1 and Dll1) and several Notch target genes (Hey1 and 2, Hes1 and 5, Cyclin D1 and D3 and Tgfb1) were measured in ex vivo xenotransplants by RTqPCR at the end of the treatment. No differences in Notch2 mRNA levels (which measures both active and membrane domains) or Notch ligands were found in response to DAPT treatment in vivo (Fig. 3A). The target gene Hey 2 was markedly decreased $(P=0.020)$, while no differences were encountered for Hey1, Hes1, Cyclin D1, Cyclin D3 or Tgfb1 mRNA expression (Fig. 3B and C). On the other hand, Hes5 and Dlk1 could not be detected in the xenotransplants (not shown).
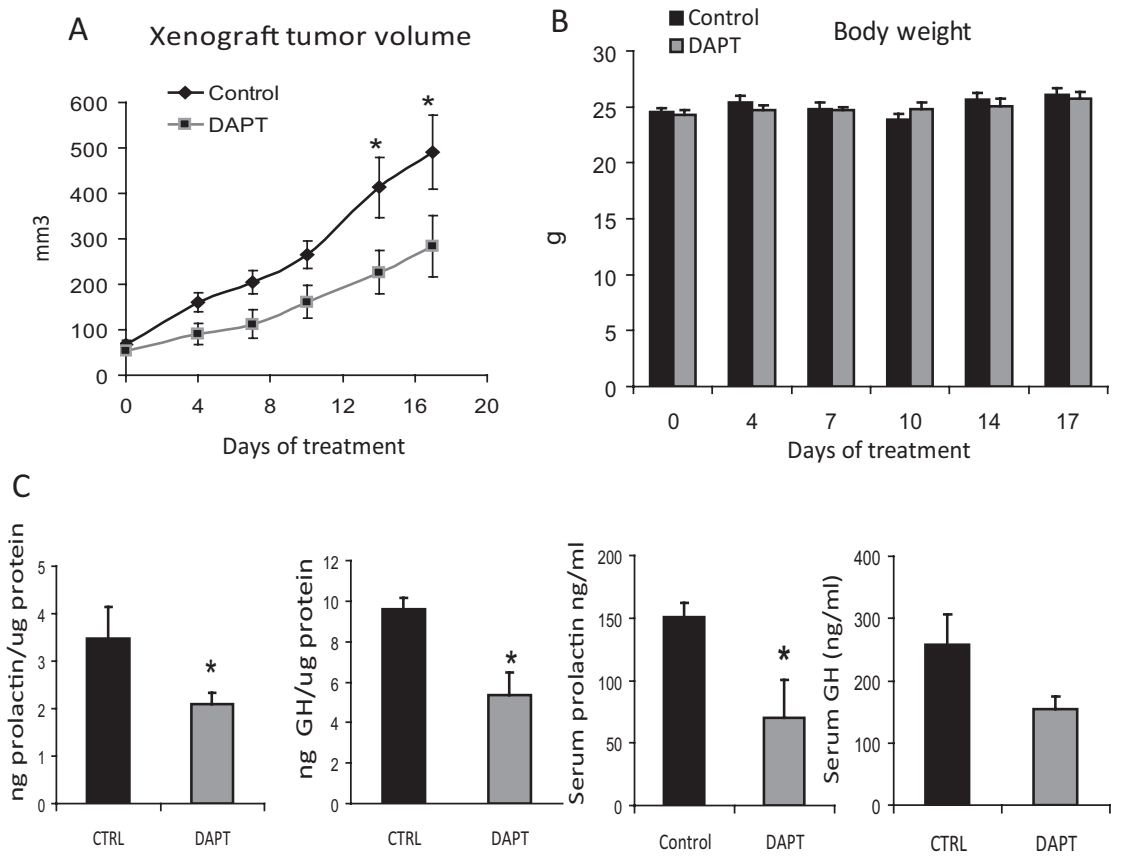

\section{Figure 1}

Notch signaling inhibition decreased xenograft volume and prolactin and $\mathrm{GH}$ tumor content in GH3 inoculated Nude mice. (A) Tumor volume (in $\mathrm{mm}^{3}$ ) in DAPT and vehicle-treated GH3 inoculated Nude mice. DAPT treatment $(8 \mathrm{mg} / \mathrm{kg}$, three times a week) was begun on day indicated as 0 . ${ }^{*} P \leq 0.05 . N=11$ control, and 12 DAPT. (B) Body weight was not modified by the treatment. (C) Prolactin and GH content in the excised tumor (ng prolactin/ $\mu$ g protein), and serum prolactin and $\mathrm{GH}$ on day $17(\mathrm{ng} / \mathrm{mL}) . N=11$ and 12 for hormone content, and 10 and 10 for serum hormones, control and DAPT, respectively. ${ }^{*} P \leq 0.05$, DAPT vs control. 
A
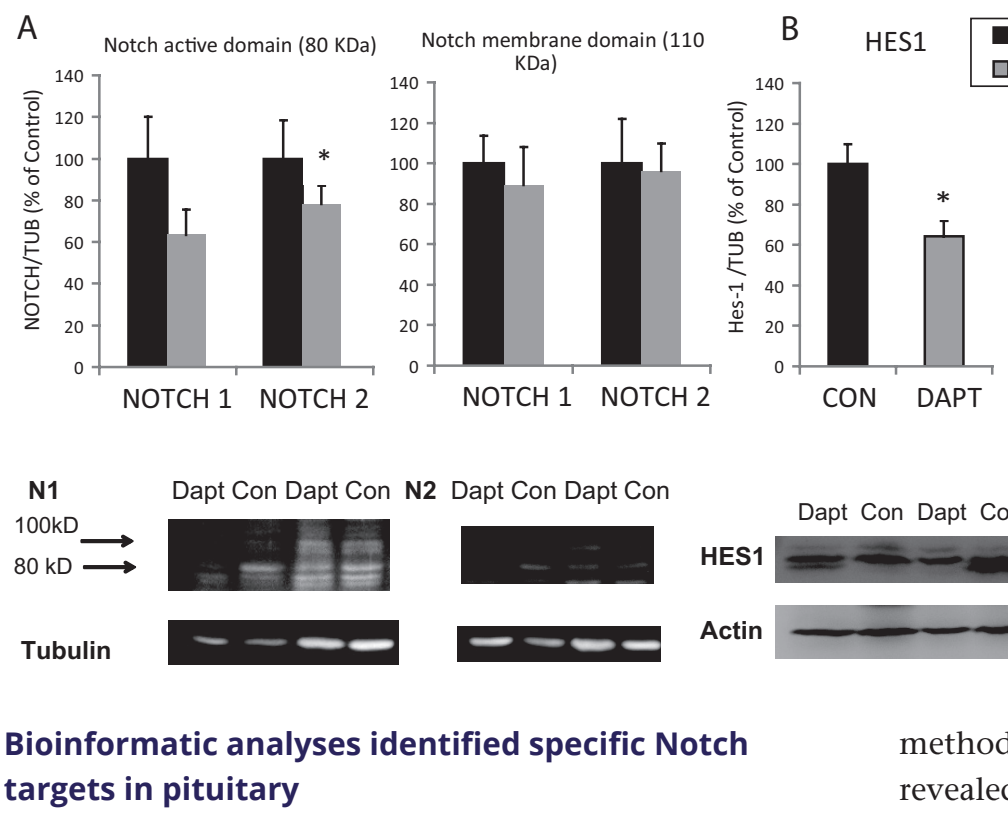

The results prompted us to search for additional Notch target genes in pituitary tissue. To that end we undertook a bioinformatic approach which consisted in analyzing the information of existing ChIP-seq data to infer putative Notch1-bound regulatory regions in pituitary cells. For this purpose, we first defined 53,695 active regulatory regions in pituitary GC cells as those genomic regions co-enriched for H3K4me1 and H3K27ac signals, as previously reported (Heintzman et al. 2007, Pasquali et al. 2014). In these regions, 2699 putative Notch1-bound sites were identified, that resulted from the intersection of regulatory regions in GC cells with Notch1-binding sites (lifted over from T-ALL, see Materials and methods). The rationale for this choice was that, given that Notch ChIP-seq in pituitary samples was not available, some of the Notch-binding sites in other tissue samples could overlap with those of pituitary cells, as long as both cell types have accessible chromatin (as in the case for the active regulatory regions profiled in GC cells). We are aware that this approach may not detect all tissuerelevant Notch1-binding sites in pituitary cells. Rather, it was useful in the context in which it was applied, to infer a subset of regions that might have a shared relevant role in tumorigenesis not only in T-ALL and pituitary, but potentially in other tissues. And, furthermore, in order to assess the relevance of the genes analyzed for the function of pituitary cells, we checked for the presence of Pit1-binding sites, a pituitary-specific transcription factor, at their nearby regulatory regions.

Then, the genes associated with the putative Notch1bound regulatory regions in GC cells (see Materials and

\begin{abstract}
Figure 2
DAPT treatment decreased Notch 2 intracellular domain and the target gene Hes1. (A) Effect of DAPT treatment on NOTCH 1 and 2 intracellular domains ( $80 \mathrm{kDa}$, Western blot), and NOTCH 1 and 2 membrane domain (110 kDa, Western blot) in tumors excised after 17 days of DAPT treatment. ${ }^{*} P \leq 0.05$, DAPT vs control, $N=11$ and 12 for NOTCH 1, and 7 and 8 for NOTCH 2. (B) Effect of DAPT treatment on the target HES1 (Western blot), $N=11$ and $12, P=0.033$. Below representative blots for Notch1 (N1, left) Notch 2 (N2, middle) and HES1 (right); Con, Control.
\end{abstract}

methods) were functionally annotated. Our results revealed, among others, significant enrichment for categories related to 'Genes involved in positive regulation of mRNA catabolic process' ( $P=1.1 \mathrm{E}-7)$ and 'histone lysine methylation' $(P=5.8 \mathrm{E}-6)$. Noteworthy, these analyses revealed putative Notch1-target genes Btg2, Cnot1, Men1, Nr4a1 and Zfp36 with previously reported or suspected tumor suppressor functions (Rouault et al. 1996, FarioliVecchioli et al. 2007, Hafner et al. 2011, Wenzl et al. 2015, Montorsi et al. 2016).

We next compared the list of genes associated with putative Notch1-bound regulatory regions in GC cells with transcriptome information obtained by comparing human control pituitaries (six samples) and three pituitary adenomas (a PRL/GH adenoma and two GH adenomas) (Table 1 and Supplementary Table 4). We quantified gene expression from RNA-seq datasets, and by performing comparisons between Control and PRL/GH+GH adenomas, we found 1778 differentially expressed genes (Supplementary Table 4). These included BTG2, ZFP36 and NR4A1, which were significantly downregulated in human pituitary somato/somatolactotrope adenomas when contrasted to the control human pituitaries (Table 1). Noteworthy, NR4A2 and NR4A3 expression was also highly downregulated in the adenomas (Supplementary Table 4), further supporting a relevant role for the NR4A genes in suppressing adenoma development.

Figure 4 shows the epigenomic profiles for the loci containing the five putative Notch target genes in pituitary cells, which emerged from our strategy: Men1, Zpf36, Btg2, Cnot1 and Nr4a1. These five genes had active regulatory regions nearby (i.e. co-enrichment of H3K4me1, brown signal and H3K27ac, yellow signal, in the plots), and putatively bound by Notch1 (grey boxes). The presence of binding sites 
A

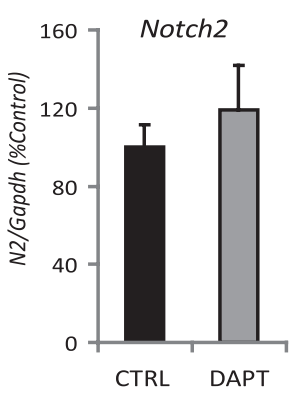

B

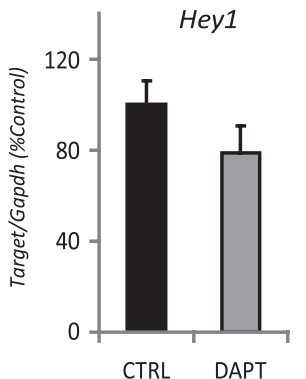

C

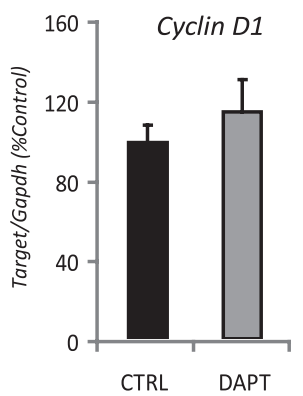

Notch ligands

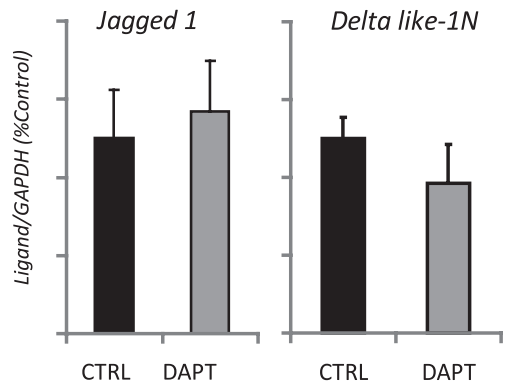

Notch target genes

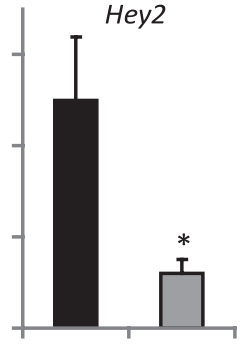

CTRL DAPT

Notch signaling

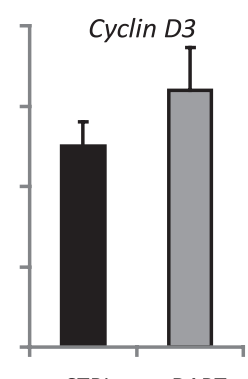

CTRL DAPT

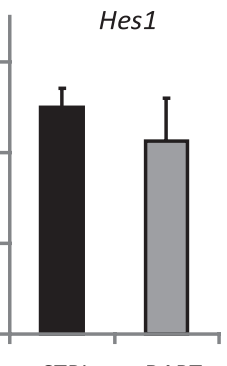

CTRL DAPT

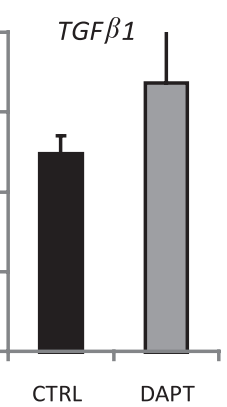

Figure 3

Effect of DAPT treatment on Notch receptors, ligands and target genes. (A) mRNA levels of Notch 2 receptor, and the ligands Jagged 1 and Delta like $1 \mathrm{~N}$ in xenografts from control and DAPT treated mice; (B) mRNA of Notch target genes and $(C)$ mRNA levels of Notch target genes involved in proliferation or epithelial-to-mesenchymal transition. ${ }^{*} P=0.020, N$ between 8 and 12 .

for Pit-1 (blue signal) validates pituitary specificity of the analysis). Noteworthy, active regulatory regions that could bind Notch1 were found especially in Btg2 and Nr4a1, which had 3 and 4 regions, respectively; Cnot1 and Men1 had 2 each and $Z f p 36$ had only one (Table 1 ).

Taken together, these in silico transcriptomic and epigenetic analyses prompted us to evaluate the tumor suppressors Btg2, Nr4a1, Men1, Zfp36 and Cnot1 as targets of Notch signaling in our model.

\section{DAPT treatment increased mRNA levels of the tumor suppressors Btg2 and Cnot1 in xenografts}

A direct interrogation of gene expression in GH3 cells compared to pituitary tumors originated by xenograft transplants of GH3 cells showed that all suppressor genes presented a downregulation trend in the xenografts, which indeed achieved significance for Btg2 and Nr4a1 mRNA expression levels (Fig. 5A). Conversely, in vivo inhibition of Notch (DAPT treatment) significantly increased the expression of the tumor repressor genes Btg2 and Cnot1 in the xenografts (Fig. 5B), advancing them as potential mediators of the DAPT-induced pituitary tumor growth inhibition and suggesting new putative therapeutic targets for pituitary adenoma treatment. mRNA but not protein levels were evaluated in the absence of adequate commercial antibodies for all transcription factors, therefore, results should be interpreted with caution.

\section{DAPT treatment decreased in vivo angiogenesis in xenotransplants}

Immunohistochemical analysis of xenotransplants at the end of treatment showed that microvascular CD31+relative area was reduced by DAPT (Fig. 6A), with no significant differences in vessel size or density (Fig. 6B and C). Moreover, aSMA+ vascular area and vessel size but

Table 1 Transcriptomic analysis of selected genes based on a combined differential gene expression (control pituitaries and a somatolactotrope/somatotrope adenomas) and ChIP-seq analysis.

\begin{tabular}{|c|c|c|c|c|c|}
\hline Gene & Signaling & Control & Ad-PRL-GH/GH & q_value & $\begin{array}{l}\text { \#of Active Regulatory Regions bound by } \\
\text { Notch } 1\end{array}$ \\
\hline MEN1 & Suppressor & 22.5 & 17.5 & N.S. & 2 \\
\hline ZFP36 & Suppressor & 258.8 & 22.0 & 0.011 & 1 \\
\hline BTG2 & Suppressor & 276.5 & 18.4 & 0.002 & 3 \\
\hline CNOT1 & Suppressor & 30.1 & 29.8 & N.S. & 2 \\
\hline NR4A1 & Suppressor & 1046.1 & 12.0 & 0.002 & 4 \\
\hline
\end{tabular}

$q$ values indicate significant differences between transcriptomes as evaluated by Trapnell et al. (2012). The number of Active Regulatory Regions putatively bound by Notch 1 (determined by ChIP-seq analyses as described in Materials and methods) is also shown. Ad-PRL-GH/GH, somatolactotrope and somatotrope adenomas.

https://erc.bioscientifica.com https://doi.org/10.1530/ERC-18-0337 (c) 2019 Society for Endocrinology Published by Bioscientifica Ltd. Printed in Great Britain 

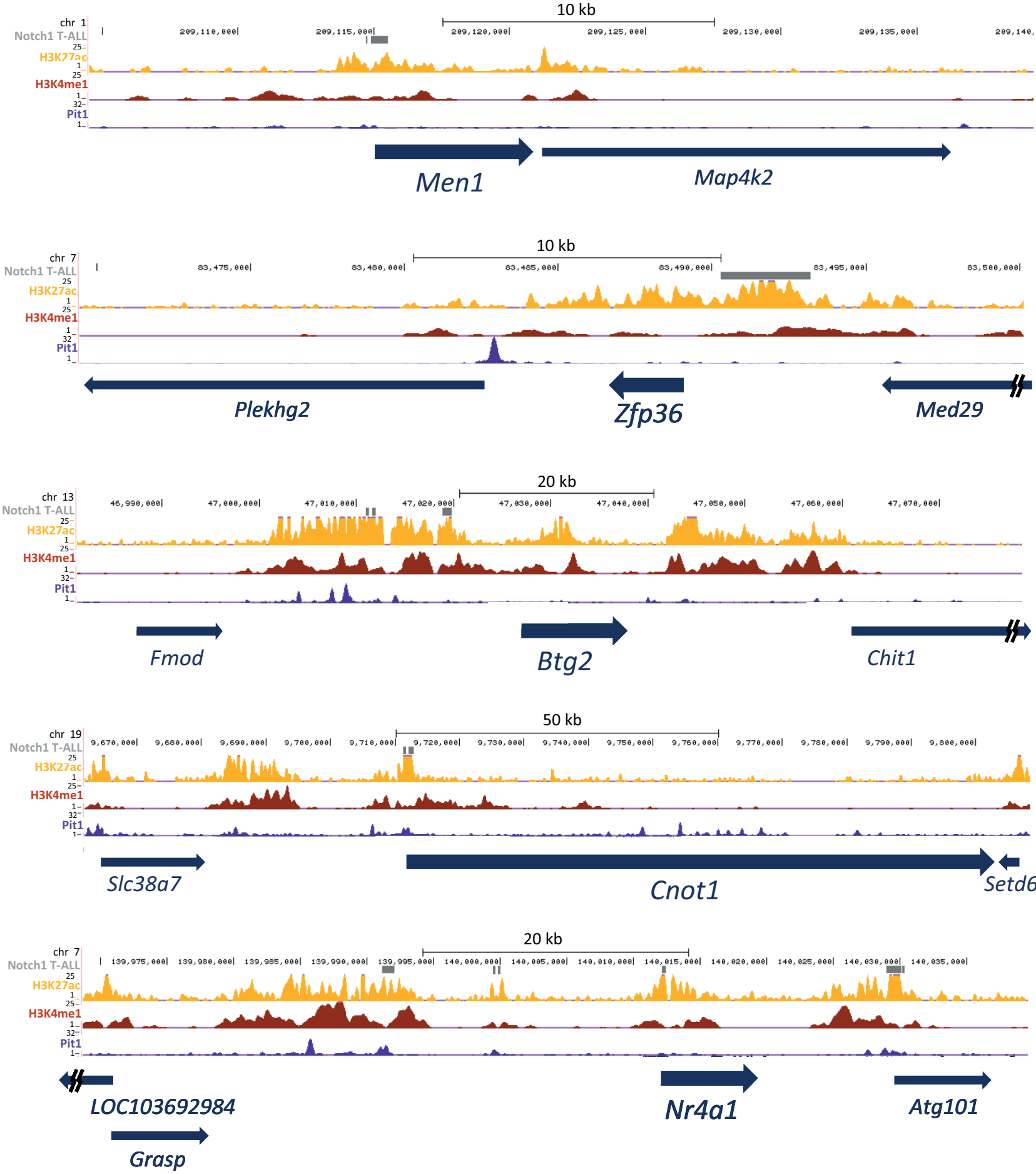

Figure 4

Genome Browser screenshots showing the epigenomic profile in the vicinity of selected genes. The enrichment profiles for H3K4me1, H3K27ac and Pit1 in GC cells, as well as the putative binding sites for Notch1 (gray boxes on top) are presented. A full colour version of this figure is available at https://doi. org/10.1530/ERC-18-0337. 

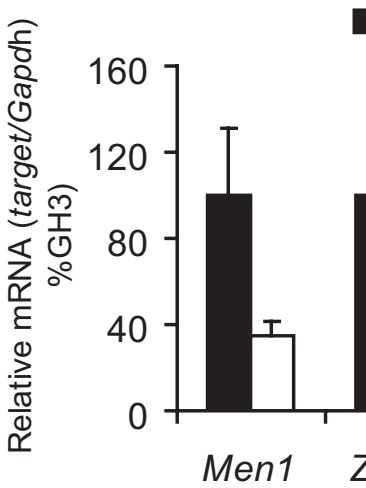

$\mathrm{GH} 3$

Tumor

B
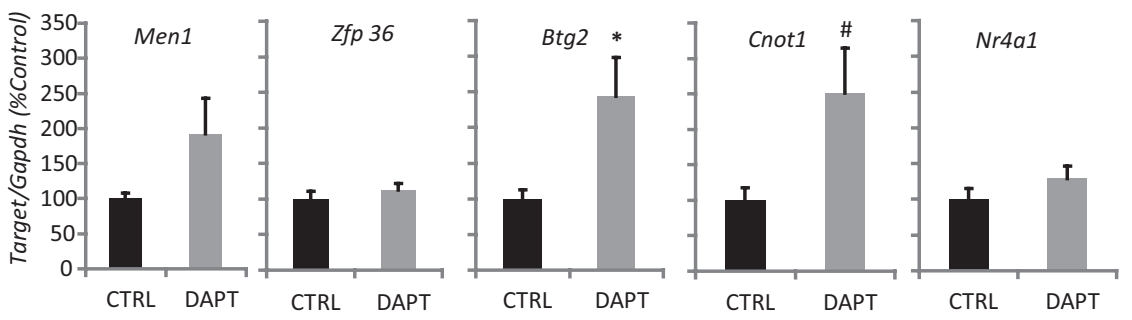
Figure 5
DAPT treatment increased the tumor suppressors Btg2 and Cnot1. (A) Comparative mRNA levels of rat Men1, Zfp36, Btg2, Cnot1 and Nr4a1 in GH3 cells and xenografts resulting from $\mathrm{GH} 3$ inoculation (tumor). ${ }^{*} P \leq 0.020, N 3$ and 3 . (B) Effect of DAPT treatment on mRNA levels of Notch targets in excised tumors at the end of the treatment. ${ }^{*} P \leq 0.01$, and $\# P=0.06 ; N 7$ and 8 , control and DAPT, respectively.

not microvessel density were decreased in xenotransplants of DAPT-treated mice (Fig. 6D and E). These findings suggest an anti-angiogenic effect of Notch inhibition in pituitary xenotransplants.

\section{Effect of in vitro DAPT treatment on Notch system components}

We next tested a direct effect of DAPT on Notch signaling in GH3 cells. After a 48-h incubation period, DAPT $(10 \mu \mathrm{M})$ decreased N2ICD but not HES1 protein or NOTCH2 membrane domain (Fig. 7A). mRNA levels of the target gene Hes 1 was also decreased in vitro by DAPT treatment (at 1 and $5 \mu \mathrm{M}$ : Fig. 7B) while no significant differences were found for Jag1, and the target genes Hey1 and 2, Cyclin 3 and Tgf b1 (Fig. 7B and not shown).

\section{DAPT decreased hormone secretion in cultured GH3 cells}

We evaluated prolactin and GH secretion after in vitro DAPT treatment for 24 and $48 \mathrm{~h}$ of GH3 cell cultures.
A
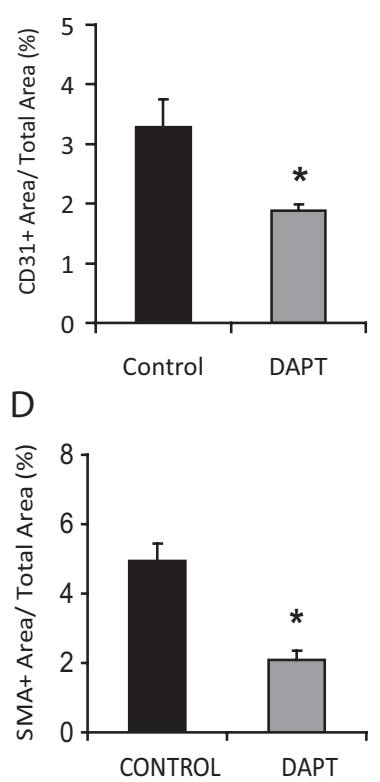

CONTROL
B

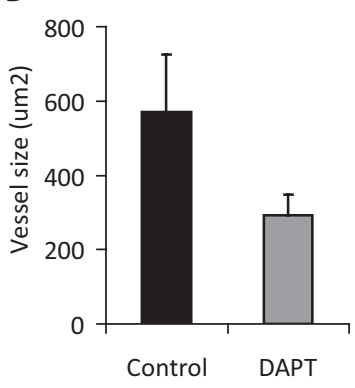

E

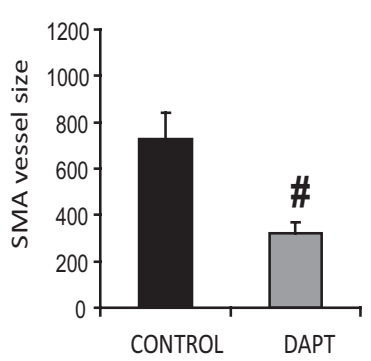

C

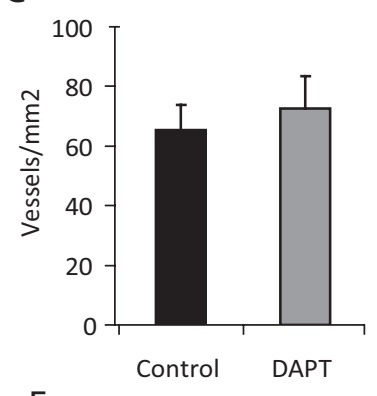

F

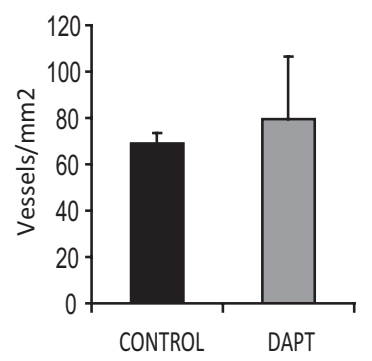

Figure 6

DAPT treatment decreased angiogenesis in $\mathrm{GH} 3$ xenografts. Effect of DAPT treatment on (A) CD31+ vessel area/total area \%, (B) average vessel size $\left(\mu \mathrm{m}^{2}\right)$ and $(\mathrm{C})$ microvessel density (number of vessels per $\mathrm{mm}^{2}$ in immunohistochemical evaluation of excised tumors at the end of the treatment. ${ }^{*} P=0.046 ; N 4$ and 4 , control and DAPT, respectively. (D, E and F) aSMA vessel area/ total area $\%$, average vessel size $\left(\mu \mathrm{m}^{2}\right)$, and microvessel density, respectively. ${ }^{\star} P=0.015$; $\# P=0.052 ; N 3$ and 3, control and DAPT, respectively. 


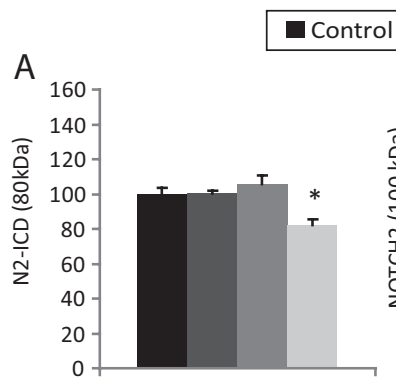

B
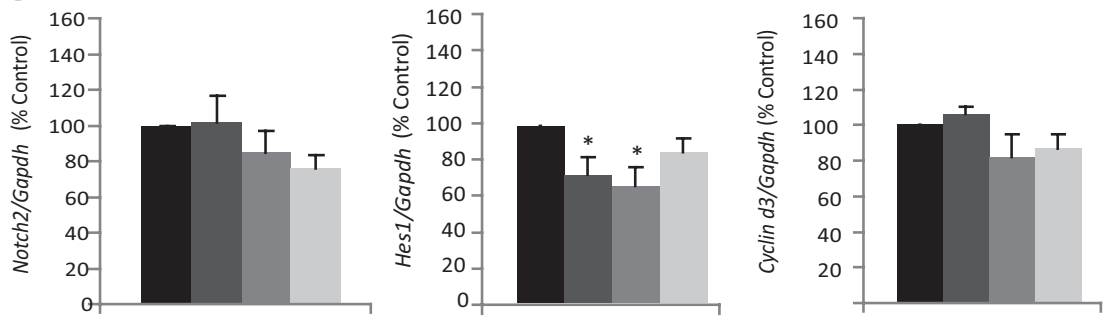

\section{Figure 7}

In vitro DAPT treatment decreased NOTCH2 intracellular domain and Hes1 mRNA levels in GH3 cells. (A) Effect of 48-h treatment with DAPT $(1,5$ and $10 \mu \mathrm{M})$ on active and membrane Notch 2 receptor ( 80 and $100 \mathrm{kDa}$ respectively), and Hes-1 measured by Western blot analysis. $N=4$ independent cultures, of duplicate samples. (B) Effect of DAPT (1, 5 and $10 \mu \mathrm{M}$ ) on mRNA levels of Notch signaling components. $N=4$ independent cultures of duplicate samples. ${ }^{*} P \leq 0.05$ vs control group.
Prolactin secretion was decreased at 24 and $48 \mathrm{~h}$ by DAPT incubation in a concentration-related manner (Fig. 8A). On the other hand, no significant differences were observed for GH secretion (Fig. 8B).

\section{DAPT decreased proliferation and prevented cell motility in $\mathrm{GH} 3$ cells in vitro}

DAPT $(10 \mu \mathrm{M})$ decreased cellular proliferation, as measured by MTS assay, at 24 but not at $48 \mathrm{~h}$ of incubation (Fig. 9A).

Finally, DAPT $(10 \mu \mathrm{M})$ prevented cell motility or wound healing in GH3 cells at 24, 48 and $72 \mathrm{~h}$ of incubation as evaluated by a scratch assay (Fig. 9B and C). Both results indicate an active participation of Notch signaling in GH3 cell proliferation and migration.

\section{Discussion}

Various components of the Notch pathway are expressed during pituitary development, including Notch2 and 3 receptors, the ligand Jagged 1 and the downstream effector Hes1 (Raetzman et al. 2006). NOTCH2 is expressed in the periluminal cells of Rathke's pouch that are undergoing rapid proliferation but not in the differentiated cells that are able to secrete glycoprotein hormones (Raetzman et al. 2006), and its expression, as well as that of several Notch family members, decrease as pituitary development proceeds, indicating an inverse correlation with cell differentiation (Raetzman et al. 2004). Nevertheless, in the adult pituitary gland, components of the Notch signaling pathway persist, particularly in locations containing progenitor/stem cells, both in hormone-producing and hormone-null cells (Chen et al. 2005, 2006, Kelberman etal. 2009, Tando et al. 2013, Mertens et al. 2015, Perrone et al. 2017). This aspect is in line with the role of Notch in maintaining progenitor cells in an undifferentiated state (as documented in the brain and intestine) and may be important in pituitary plasticity.

Insights into pituitary tumorigenesis may be gained from studies on pituitary development and cell differentiation. Genes that are important during development or differentiation often contribute to tumor promotion, survival or resistance when they become uncontrolled. Indeed, cancer may be considered a developmental disease, and pathways such as Notch that can affect cell fate, and the balance between differentiation, apoptosis and proliferation, are known to be involved in tumorigenesis. Therefore, the Notch pathway is evolving into an actively pursued drug target in cancer.

In numerous types of experimental models of cancer blocking Notch activation by $\gamma$-secretase inhibitors, like DAPT and others, was effective in reducing proliferation or resistance to chemotherapeutics (Espinoza \& Miele 2013). For example, in colon cancer cells, (Akiyoshi et al. 2008), in ER-negative breast cancer (Lee et al. 2008), glioma stem cells (Wang et al. 2010), prostate cancer (Wang et al. 2011), renal cell carcinoma (Sjolund et al. 2008) or experimental brain tumors (Gilbert et al. 2010). Nevertheless, it has become apparent that altered Notch status may be associated with both pro- and anti-tumor-suppressive roles. For example, it had a suppressive role in the formation of vascular tumors in the liver, in mouse keratinocytes, pancreatic and hepatocellular carcinoma (Koch \& Radtke 2010, Liu et al. 2011, Ranganathan et al. 2011), 


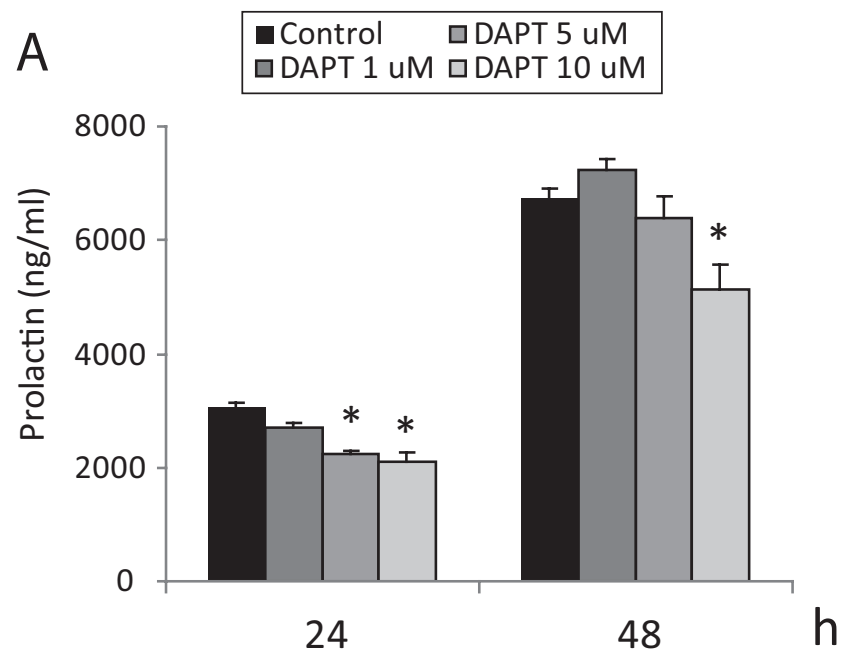

B

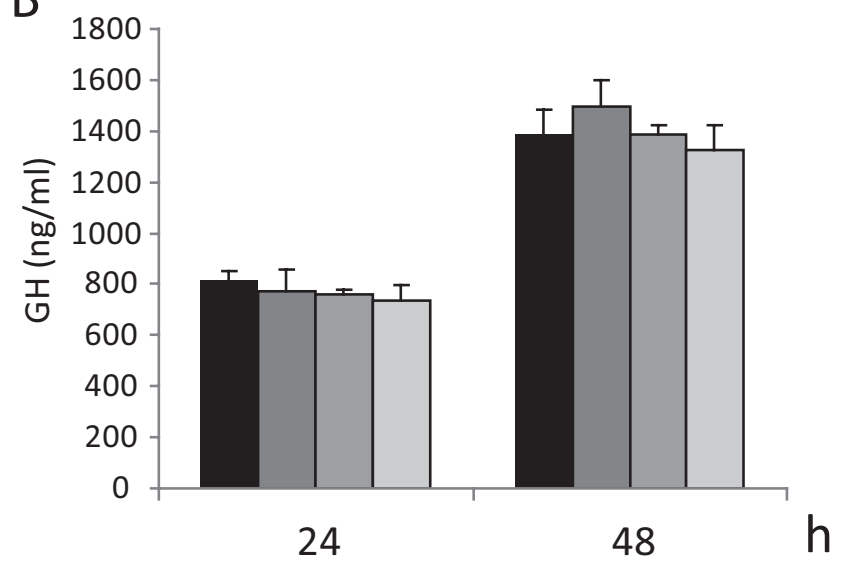

Figure 8

In vitro DAPT treatment decreased prolactin secretion by GH3 cells. Effect of DAPT $(1,5$ and $10 \mu \mathrm{M})$ on (A) prolactin and (B) GH secretion by GH3 cells cultured in vitro for 24 or $48 \mathrm{~h} . \mathrm{N}=3$ independent cultures, of duplicate samples. ${ }^{*} P \leq 0.05$ vs control group.

among others. Therefore, it is important to determine the functional direction of Notch activation in each tumor type as its effects are dependent on the cellular context and the interaction with other signal transduction pathways. In this context, the role of Notch signaling in pituitary adenoma development and growth has not yet been addressed. Recent evidence revealed a differential sensitivity to Notch activation within and between pituitary endocrine cell lineages during development (Cheung et al. 2018), which further stresses the necessity to establish its role within each pituitary adenoma histotype.

Descriptive but not functional data of Notch pathway in pituitary tumors suggest that Notch may be implicated in the pathogenesis of human pituitary adenomas. By microarray analysis, Evans et al. identified increased
NOTCH3, DLK1 and decreased HES1 in prolactinomas compared to normal pituitaries (Evans et al. 2008). Data from Runchun et al. indicated non-significant increases in NOTCH3 and JAGGED1 expression in prolactinomas compared to normal pituitaries; however, only 4 prolactinomas were used in the study (Lu et al. 2013). Functional studies of pituitary tumor generation or maintenance using Notch inhibition are lacking in prolactinomas, somatotropinomas, somatolactotropinomas or corticotropinomas. One in vitro study was performed by Tando et al. (2013) who described that DAPT treatment of anterior pituitary cells in culture decreased Hes1 mRNA levels, and proliferation but only in the non-hormone-producing S100 cells of the S100b-GFP rat (Tando et al. 2013). Nevertheless, the fact that many pituitary cell types co-exist in the normal pituitary is an important caveat that should be kept in mind when interpreting results presented in this work, as in the other mentioned studies that compare tumoral and normal pituitaries. To address this limitation, we performed a combined transcriptomic and epigenomic approach, which allowed focusing our functional analysis and ultimately validate part of our findings.

In a previous study, we showed that in prolactinomas which develop in lacDrd2KO female mice, Notch1 and Notch 3 mRNA levels and also NOTCH 2-3 membrane and N1ICD were highly expressed compared to pituitaries of control animals (Perrone et al. 2017). We also determined that all four Notch receptors were expressed in somatolactotrope GH3 cells, and that N2ICD, and Jagged1, Dll1 and Hey1 were upregulated in the cell line compared to rat pituitary cells. We therefore sought to determine if inhibition of Notch signaling would modify GH3 xenotransplant growth and angiogenesis in Nude mice. We used DAPT a $\gamma$-secretase inhibitor, which prevents cleavage of intracellular Notch domains, and therefore, modifies target-specific transcription factors in the nucleus.

Our results show that inhibition of $\gamma$-secretase lowered tumor burden by $42 \%$ and decreased tumor angiogenesis by $26 \%$ in somatolactotrope xenotransplants. It effectively decreased active N2ICD formation, expression of the target protein HES1 and the Hey 2 gene indicating a blockade of Notch signaling, and suggesting a novel strategy in the treatment of aggressive or resistant prolactinomas. Nevertheless, the lack of specificity of targeting $\gamma$-secretase may constitute a significant limitation (Lamy et al. 2017), and therefore, specific tumor-related targets activated by Notch signaling in different tumor types are under the spotlight. The classical Notch targets, such as HES and 


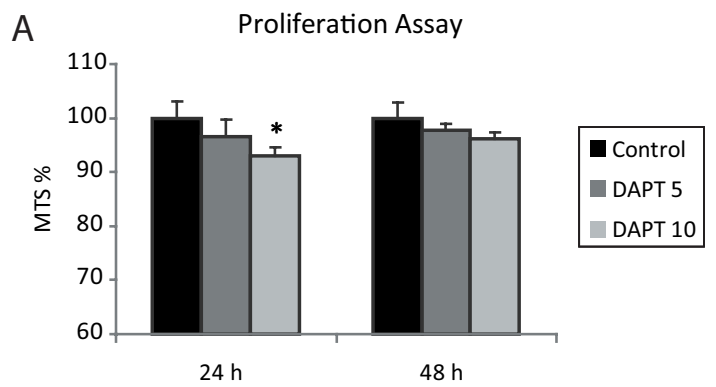

B

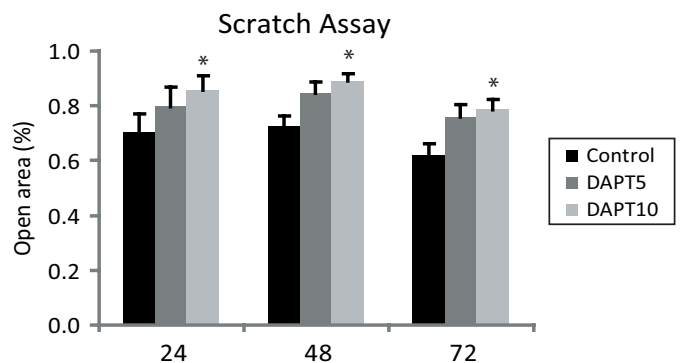

C

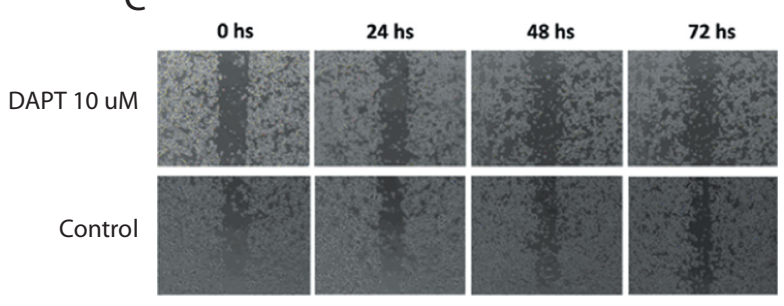

\section{Figure 9}

In vitro DAPT treatment decreased proliferation and migration in $\mathrm{GH} 3$ cells. (A) Effect of 24 and 48-h DAPT treatment (1, 5 and $10 \mu \mathrm{M})$ on cell proliferation assessed by MTS assay. ${ }^{*} P \leq 0.05$ vs control group, $N=4$ independent cultures of duplicate samples; (B) Effect of 24, 48 and 72-h treatment with DAPT $(1,5$ and $10 \mu \mathrm{M})$ on remaining open area in culture in a scratch assay (expressed as $\%$ of initial open area). $* P \leq 0.05$ vs control group, $N=4$ independent cultures of duplicate samples. (C) Representative images.

HEY families, are recurrently found in many tissues, while others seem to be tissue specific. In this context, the inventory of Notch targets has begun to expand (Hurlbut et al. 2009). Recent gene expression studies combined with chromatin immunoprecipitation arrays revealed the existence of a large number of genes that can directly be regulated by Notch in different solid tumors (Koch \& Radtke 2010). The challenge will be to identify and distinguish driver target genes from passenger ones in each cancer type. In this context, our bioinformatic approach combining epigenomic and transcriptomic information obtained from public databases uncovers potential genes activated by Notch, which may be specific to pituitary adenoma development and growth.

By epigenomic profiling of active regulatory regions (enhancers and promoters, which might also present mild enrichments in H3K4me1 Heintzman et al. 2007) in a pituitary somatotrope cell line we were able to infer putative Notch-bound regions and novel target genes. Combining this information with the differential gene expression profiles obtained from human normal and somatotrope+somatolactotrope pituitary samples allowed us to focus on some interesting putative Notch targets genes, whose regulation was next validated experimentally. Epigenetic analysis revealed that the genes Btg2, Nr4a1, Men1, Zfp36 and Cnot1, presented active regulatory regions associated to Notch-binding sites. Particularly, the Notch-related tumor suppressor genes selected by epigenetic analysis, Btg2, Zpf36 and Nr4a1 were downregulated in all somatotrope and somatolactotrope adenomas when compared to normal pituitaries. Therefore, these in silico transcriptomic and epigenomic analyses allowed us to select several tumor suppressors of Notch signaling in pituitary tissue to be evaluated in our study, namely Btg2, Nr4a1, Men1, Zfp36 and Cnot1.

Our results point to $B t g 2, N r 4 a 1$ and Cnot1 as possible players in GH3 xenograft development and growth. In particular, Btg2 mRNA expression was lower in xenografted GH3 cells compared to the parental line, and DAPT increased its expression in the xenograft in parallel with the inhibition of tumor volume. Nr4a1 was also decreased in xenotransplants compared to the parental line, similar to results uncovered in RNA-seq analysis comparing human somatolactotrope adenomas and normal pituitaries, but its expression was not modified by DAPT treatment. Finally, Cnot1, also a suppressor gene was increased by DAPT treatment in the pituitary xenografts.

B-cell translocation gene 2, BTG2, is a tumor suppressor gene whose overexpression leads to decreased proliferation and arrest of cells at the G1 phase of the cell cycle (Rouault et al. 1996). It is downregulated in preneoplastic and neoplastic lesions in various cancers (Farioli-Vecchioli et al. 2007, Mao et al. 2015), and it intersects with the Notch pathway (Farioli-Vecchioli et al. 2014). It is found in the embryonic and adult anterior pituitary (Terra et al. 2008), and, using the NCBI database (http://www.ncbi.nlm.nih.gov/Genbank/) to analyze the differentially expressed genes in plurihormonal and $\mathrm{GH}$ pituitary adenomas compared with healthy pituitaries, BTG2 was found downregulated (Jiang et al. 2010, 2012). In accordance, our experimental and bioinformatic results support its role as a tumor suppressor in the pituitary and suggest its regulation by Notch.

Nuclear receptor (NR) subfamily 4 group A (NR4A) is a family of three highly homologous orphan nuclear 
receptors that have multiple physiological and pathological roles. These NRs are reportedly dysregulated in multiple cancer types, with many studies demonstrating prooncogenic roles for NR4A1 (Nur77) and NR4A2 (Nurr1), while tumor suppression roles have been suggested for NR4A1 and NR4A3 (Nor-1) in leukemia (Wenzl et al. 2015). In the pituitary, NR participates in CRH-induced proopiomelanocortin expression in corticotrophs (Kovalovsky et al. 2002), and Nur77 gene expression levels may be critical in the different autonomy of ACTH production between Cushing's syndrome and subclinical Cushing's syndrome (Tabuchi et al. 2016). Our results demonstrate that Nr4a1 is decreased in GH3 xenografts, and our re-analysis of public RNA-seq datasets showed that expression of all NR4A genes (NR4A1, NR4A2 and NR4A3) is severely downregulated in somatoprolactinomas and somatotropinomas when compared to normal human pituitaries, indicating a possible suppressive role for this gene in the pituitary.

CNOT1 is a scaffold protein of the CCR4-NOT complex. This complex participates in various physiological functions, including cell proliferation, apoptosis, mitotic progression, fertility, bone formation, heart function, energy metabolism (Zukeran et al. 2016) and miRNA-mediated mRNA repression (Hafner et al. 2011). Furthermore, CCR4-NOT deadenylase activity contributes to induction of pluripotent stem cells (Zukeran et al. 2016). No relation has been yet established with pituitary regulation, and our results show that it can be modulated by Notch inhibition to potentially activate a putative tumor-suppressive role.

Menin is a putative tumor suppressor associated with multiple endocrine neoplasia type 1 (MEN-1 syndrome), and the development of tumors in target neuroendocrine tissues. Even though epigenetic analysis suggested that it may be regulated by Notch signaling, no difference for this gene was found in DAPT-treated tumors. Finally, the mRNA-destabilizing protein ZFP36, which had been previously described as a tumor suppressor and impairs the epithelial-to-mesenchymal transition (Montorsi et al. 2016) was not modified in the present experimental model.

Among the signaling pathways involved in tumor angiogenesis, Notch signaling stands as a crucial player. This pathway does not just participate in physiological angiogenesis during development, wound healing or pregnancy, but is also involved in pathological vascularization, such as in tumor angiogenesis. Importantly, experimental evidence revealed that Notch may be involved in anticancer drug resistance, indicating that targeting this pathway could be a novel therapeutic approach to the treatment for cancer by overcoming drug resistance. Notch receptors and ligands are widely expressed in the vasculature, but as described for tumor proliferation, it has been reported that Notch has angiogenic properties, but may also act in anti-angiogenesis in vascular tumors (Liu et al. 2011). It is therefore paramount to validate its angiogenic action in each tumor type.

We show that DAPT treatment decreased microvascular area determined by $\mathrm{CD} 1^{+}$and aSMA+cells, indicating that in pituitary tumors Notch increases angiogenesis, as described for neck squamous cell or breast carcinoma models (Zeng et al. 2005, Funahashi et al. 2008), among others. This is a novel finding for pituitary tumors and should be highlighted in the context of anti-angiogenic therapies, which have been successful in experimental prolactinomas (Luque etal. 2011), as well as in a particularly aggressive Cushing tumors (Ortiz et al. 2012, Touma et al. 2017). Furthermore, the fact that DAPT reduced the expression of the smooth muscle cell marker $\alpha \mathrm{SMA}$ is an indication that the Notch system may participate in vasculature remodeling and vessel maturation through interaction of mural and endothelial cells, as described for NOTCH3 (Liu et al. 2009).

We have previously shown that expression of different components of the Notch system vary when comparing GH3 in vivo tumors generated by GH3 inoculation, and GH3 cells. GH3 tumors showed higher activation of NOTCH1 and lower of NOTCH2 receptor than isolated GH3 somatolactotropic cells (Perrone et al. 2017). Differences in Dll1 ligand expression were also observed, suggesting that tumor vasculature and/or extracellular matrix components, which are absent in cell lines may be important modulators of Notch signaling in xenografted somatoprolactinomas. The extracellular matrix plays a critical role in tumor development in various cancers, and its importance in xenograft growth cannot be disregarded. Therefore, in order to ascertain whether the Notch system cell-autonomously participated in GH3 tumor development, we performed in vitro studies inhibiting $\gamma$-secretase directly in cultured GH3 cells. Our results clearly indicate that Notch signaling in GH3 cells is positively involved in cellular proliferation and migration. Similarly, results using DAPT treatment of pituitary explants in vitro or postnatal mice in vivo suggested that Notch signaling allows pituitary cell proliferation during postnatal development, even though a direct effect on dispersed cells was not verified in this study (Nantie et al. 2014). Furthermore, we show that inhibition of Notch activation led to decreased prolactin 
but not GH secretion, suggesting a differential activity in the production of both hormones. In human GeneChip microarrays and proteomics analyses, increased expression of NOTCH3 was found in prolactin and non-functioning secreting adenomas while in somatotropinomas, a significantly reduced expression of NOTCH3 was found (Moreno et al. 2005, Evans et al. 2008). Furthermore, in GH3 cells, it was described that the non-canonical Notch ligand Dlk1 is expressed in some clones, in which it represses $\mathrm{GH}$ expression and secretion but does not affect prolactin production (Ansell et al. 2007). Therefore, it may be hypothesized that Notch manipulation may have a differential outcome for prolactin and GH-secreting tumors.

Personalized molecular treatments based on specific genetic markers may improve diagnosis, treatment and outcome in resistant and aggressive somatotropinomas and somatoprolactinomas. In this context, salient features identify Notch as a candidate diagnostic and prognostic biomarker and a promising target for cancer therapy (Espinoza \& Miele 2013). Currently, most Notch-directed therapies involve the use of $\gamma$-secretase inhibitors, but the lack of substrate specificity and associated toxicity found in clinical studies constitute limitations to their therapeutic use (Lamy et al. 2017). Antibodies have emerged as powerful biological therapeutics due to their specificity and efficacy; and soluble decoys which compete with natural ligands of Notch signaling but lack the transmembrane domain are being tested (Espinoza \& Miele 2013). Our results suggest that interruption of Notchselective pituitary targets might be a novel strategy when designing combinatorial treatment regimens in aggressive or atypical prolactin and GH-secreting adenomas.

\section{Supplementary data}

This is linked to the online version of the paper at https://doi.org/10.1530/ ERC-18-0337.

\section{Declaration of interest}

The authors declare that there is no conflict of interest that could be perceived as prejudicing the impartiality of the research reported.

\section{Funding}

This work was supported by grants from Agencia Nacional de Promoción Científica y Tecnológica, Argentina: PICT 330-2013; PICT 901-2013; PICT 1343-2015; PICT 526-2016, Fundación Rene Barón, Fundación Williams, Consejo Nacional de Investigaciones Científicas y Técnicas and Universidad Nacional del Noroeste de la Provincia de Buenos Aires: PIO CONICETUNNOBA 2015-2016 and SIB UNNOBA 2015-3160 and collaboration grant between MINCYT and Fund for Scientific Research (FWO) - Flanders (Belgium).

\section{Acknowledgements}

The authors thank the National Institute of Diabetes and Digestive and Kidney Diseases' National Hormone and Pituitary Program and Dr A F Parlow for prolactin and GH RIA kit. C Cristina and D Becu-Villalobos contributed equally.

\section{References}

Akiyoshi T, Nakamura M, Yanai K, Nagai S, Wada J, Koga K, Nakashima H, Sato N, Tanaka M \& Katano M 2008 Gamma-secretase inhibitors enhance taxane-induced mitotic arrest and apoptosis in colon cancer cells. Gastroenterology 134 131-144. (https://doi. org/10.1053/j.gastro.2007.10.008)

Ansell PJ, Zhou Y, Schjeide BM, Kerner A, Zhao J, Zhang X \& Klibanski A 2007 Regulation of Growth Hormone expression by Delta-like protein 1 (Dlk1). Molecular and Cellular Endocrinology 271 55-63. (https://doi.org/10.1016/j.mce.2007.04.002)

Artavanis-Tsakonas S \& Muskavitch MA 2010 Notch: the past, the present, and the future. Current Topics in Developmental Biology 92 1-29. (https://doi.org/10.1016/S0070-2153(10)92001-2)

Avila JL \& Kissil JL 2013 Notch signaling in pancreatic cancer: oncogene or tumor suppressor? Trends in Molecular Medicine 19 320-327. (https://doi.org/10.1016/j.molmed.2013.03.003)

Bray SJ 2006 Notch signalling: a simple pathway becomes complex. Nature Reviews. Molecular Cell Biology 7 678-689. (https://doi. org/10.1038/nrm2009)

Castro CP, Giacomini D, Nagashima AC, Onofri C, Graciarena M, Kobayashi K, Paez-Pereda M, Renner U, Stalla GK \& Arzt E 2003 Reduced expression of the cytokine transducer gp130 inhibits hormone secretion, cell growth, and tumor development of pituitary lactosomatotrophic GH3 cells. Endocrinology 144 693-700. (https:// doi.org/10.1210/en.2002-220891)

Chen J, Hersmus N, Van DV, Caesens P, Denef C \& Vankelecom H 2005 The adult pituitary contains a cell population displaying stem/ progenitor cell and early embryonic characteristics. Endocrinology 146 3985-3998. (https://doi.org/10.1210/en.2005-0185)

Chen J, Crabbe A, Van DV, \& Vankelecom H 2006 The notch signaling system is present in the postnatal pituitary: marked expression and regulatory activity in the newly discovered side population. Molecular Endocrinology 20 3293-3307. (https://doi.org/10.1210/ me.2006-0293)

Cheung L, Le Tissier P, Goldsmith SG, Treier M, Lovell-Badge R \& Rizzoti K 2018 NOTCH activity differentially affects alternative cell fate acquisition and maintenance. Elife 7. (https://doi.org/10.7554/ eLife.33318)

Ellisen LW, Bird J, West DC, Soreng AL, Reynolds TC, Smith SD \& Sklar J 1991 TAN-1, the human homolog of the Drosophila notch gene, is broken by chromosomal translocations in T lymphoblastic neoplasms. Cell 66 649-661. (https://doi.org/10.1016/00928674(91)90111-B)

Espinoza I \& Miele L 2013 Notch inhibitors for cancer treatment. Pharmacology and Therapeutics 139 95-110. (https://doi. org/10.1016/j.pharmthera.2013.02.003)

Evans CO, Moreno CS, Zhan X, McCabe MT, Vertino PM, Desiderio DM \& Oyesiku NM 2008 Molecular pathogenesis of human prolactinomas identified by gene expression profiling, RT-qPCR, and proteomic analyses. Pituitary 11 231-245. (https://doi.org/10.1007/ s11102-007-0082-2)

Farioli-Vecchioli S, Tanori M, Micheli L, Mancuso M, Leonardi L, Saran A, Ciotti MT, Ferretti E, Gulino A, Pazzaglia S, et al. 2007 
Inhibition of medulloblastoma tumorigenesis by the antiproliferative and pro-differentiative gene PC3. FASEB Journal 21 2215-2225. (https://doi.org/10.1096/fj.06-7548com)

Farioli-Vecchioli S, Ceccarelli M, Saraulli D, Micheli L, Cannas S, D'Alessandro F, Scardigli R, Leonardi L, Cina I, Costanzi M, et al. 2014 Tis21 is required for adult neurogenesis in the subventricular zone and for olfactory behavior regulating cyclins, BMP4, Hes1/5 and Ids. Frontiers in Cellular Neuroscience 8 98. (https://doi. org/10.3389/fncel.2014.00098)

Funahashi Y, Hernandez SL, Das I, Ahn A, Huang J, Vorontchikhina M, Sharma A, Kanamaru E, Borisenko V, Desilva DM, et al. 2008 A notch1 ectodomain construct inhibits endothelial notch signaling, tumor growth, and angiogenesis. Cancer Research 68 4727-4735. (https://doi.org/10.1158/0008-5472.CAN-07-6499)

Garcia-Tornadu I, Diaz-Torga GS, Risso G, Silveyra P, Cataldi N, Ramirez MC, Low MJ, Libertun C \& Becu-Villalobos D 2009 Hypothalamic orexin, OX1, $\alpha \mathrm{MSH}$, NPY and MCRs expression in dopaminergic D2R knockout mice. Neuropeptides 43 267-274. (https://doi.org/10.1016/j.npep.2009.06.002)

Gilbert CA, Daou MC, Moser RP \& Ross AH 2010 Gamma-secretase inhibitors enhance temozolomide treatment of human gliomas by inhibiting neurosphere repopulation and xenograft recurrence. Cancer Research 70 6870-6879. (https://doi.org/10.1158/0008-5472. CAN-10-1378)

Gordon WR, Arnett KL \& Blacklow SC 2008 The molecular logic of Notch signaling--a structural and biochemical perspective. Journal of Cell Science 121 3109-3119. (https://doi.org/10.1242/jcs.035683)

Hafner M, Ascano M Jr. \& Tuschl T 2011 New insights in the mechanism of microRNA-mediated target repression. Nature Structural and Molecular Biology 18 1181-1182. (https://doi. org/10.1038/nsmb.2170)

Harrison H, Farnie G, Howell SJ, Rock RE, Stylianou S, Brennan KR, Bundred NJ \& Clarke RB 2010 Regulation of breast cancer stem cell activity by signaling through the Notch4 receptor. Cancer Research 70 709-718. (https://doi.org/10.1158/0008-5472.CAN-09-1681)

Heintzman ND, Stuart RK, Hon G, Fu Y, Ching CW, Hawkins RD, Barrera LO, Van Calcar S, Qu C, Ching KA, et al. 2007 Distinct and predictive chromatin signatures of transcriptional promoters and enhancers in the human genome. Nature Genetics 39 311-318. (https://doi.org/10.1038/ng1966)

Hurlbut GD, Kankel MW \& Artavanis-Tsakonas S 2009 Nodal points and complexity of Notch-Ras signal integration. PNAS 106 2218-2223. (https://doi.org/10.1073/pnas.0812024106)

Jiang Z, Gui S \& Zhang Y 2010 Analysis of differential gene expression by bead-based fiber-optic array in growth-hormone-secreting pituitary adenomas. Experimental and Therapeutic Medicine 1 905-910. (https://doi.org/10.3892/etm.2010.137)

Jiang Z, Gui S \& Zhang Y 2012 Analysis of differential gene expression in plurihormonal pituitary adenomas using bead-based fiber-optic arrays. Journal of Neuro-Oncology 108 341-348. (https://doi. org/10.1007/s11060-011-0792-1)

Kelberman D, Rizzoti K, Lovell-Badge R, Robinson IC \& Dattani MT 2009 Genetic regulation of pituitary gland development in human and mouse. Endocrine Reviews 30 790-829. (https://doi.org/10.1210/ er.2009-0008)

Kent WJ, Sugnet CW, Furey TS, Roskin KM, Pringle TH, Zahler AM \& Haussler D 2002 The human genome browser at UCSC. Genome Research 12 996-1006. (https://doi.org/10.1101/gr.229102)

Koch U \& Radtke F 2010 Notch signaling in solid tumors. In Notch Signaling, edn 92, pp 411-455. (https://doi.org/10.1016/S00702153(10)92013-9) Ed R Kopan, Elsevier.

Kovalovsky D, Refojo D, Liberman AC, Hochbaum D, Pereda MP, Coso OA, Stalla GK, Holsboer F \& Arzt E 2002 Activation and induction of NUR77/NURR1 in corticotrophs by CRH/cAMP: involvement of calcium, protein kinase A, and MAPK pathways.
Molecular Endocrinology 16 1638-1651 (https://doi.org/10.1210/ mend.16.7.0863)

Lamy M, Ferreira A, Dias JS, Braga S, Silva G \& Barbas A 2017 Notch-out for breast cancer therapies. Nature Biotechnology 39 215-221 (https:// doi.org/10.1016/j.nbt.2017.08.004)

Langmead B, Trapnell C, Pop M \& Salzberg SL 2009 Ultrafast and memoryefficient alignment of short DNA sequences to the human genome. Genome Biology 10 R25. (https://doi.org/10.1186/gb-2009-10-3-r25)

Lee CW, Raskett CM, Prudovsky I \& Altieri DC 2008 Molecular dependence of estrogen receptor-negative breast cancer on a notchsurvivin signaling axis. Cancer Research 68 5273-5281. (https://doi. org/10.1158/0008-5472.CAN-07-6673)

Liu H, Kennard S \& Lilly B 2009 NOTCH3 expression is induced in mural cells through an autoregulatory loop that requires endothelialexpressed JAGGED1. Circulation Research 104 466-475. (https://doi. org/10.1161/CIRCRESAHA.108.184846)

Liu Z, Turkoz A, Jackson EN, Corbo JC, Engelbach JA, Garbow JR, Piwnica-Worms DR \& Kopan R 2011 Notch1 loss of heterozygosity causes vascular tumors and lethal hemorrhage in mice. Journal of Clinical Investigation 121 800-808. (https://doi.org/10.1172/ JCI43114)

Lu R, Gao H, Wang H, Cao L, Bai J \& Zhang Y 2013 Overexpression of the Notch3 receptor and its ligand Jagged 1 in human clinically nonfunctioning pituitary adenomas. Oncology Letters 5 845-851. (https:// doi.org/10.3892/ol.2013.1113)

Luque GM, Perez-Millan MI, Ornstein AM, Cristina C \& BecuVillalobos D 2011 Inhibitory effects of antivascular endothelial growth factor strategies in experimental dopamine-resistant prolactinomas. Journal of Pharmacology and Experimental Therapeutics 337 766-774. (https://doi.org/10.1124/jpet.110.177790)

Mao B, Zhang Z \& Wang G 2015 BTG2: a rising star of tumor suppressors (review). International Journal of Oncology 46 459-464. (https://doi.org/10.3892/ijo.2014.2765)

Mertens F, Gremeaux L, Chen J, Fu Q, Willems C, Roose H, Govaere O, Roskams T, Cristina C, Becu-Villalobos D, et al. 2015 Pituitary tumors contain a side population with tumor stem cell-associated characteristics. Endocrine-Related Cancer 22 481-504. (https://doi. org/10.1530/ERC-14-0546)

Miao Z, Miao Y, Lin Y \& Lu X 2012 Overexpression of the Notch3 receptor in non-functioning pituitary tumours. Journal of Clinical Neuroscience 19 107-110. (https://doi.org/10.1016/j.jocn.2011.07.029)

Montorsi L, Guizzetti F, Alecci C, Caporali A, Martello A, Atene CG, Parenti S, Pizzini S, Zanovello P, Bortoluzzi S, et al. 2016 Loss of ZFP36 expression in colorectal cancer correlates to wnt/B-catenin activity and enhances epithelial-to-mesenchymal transition through upregulation of zeb1, sox9 and macc1. Oncotarget 7 59144-59157. (https://doi.org/10.18632/oncotarget.10828)

Moreno CS, Evans CO, Zhan X, Okor M, Desiderio DM \& Oyesiku NM 2005 Novel molecular signaling and classification of human clinically nonfunctional pituitary adenomas identified by gene expression profiling and proteomic analyses. Cancer Research $\mathbf{6 5}$ 10214-10222. (https://doi.org/10.1158/0008-5472.CAN-05-0884)

Nantie LB, Himes AD, Getz DR \& Raetzman LT 2014 Notch signaling in postnatal pituitary expansion: proliferation, progenitors, and cell specification. Molecular Endocrinology 28 731-744. (https://doi. org/10.1210/me.2013-1425)

Ortiz LD, Syro LV, Scheithauer BW, Ersen A, Uribe H, Fadul CE, Rotondo F, Horvath E \& Kovacs K 2012 Anti-VEGF therapy in pituitary carcinoma. Pituitary 15 445-449. (https://doi.org/10.1007/ s11102-011-0346-8)

Pasquali L, Gaulton KJ, Rodriguez-Segui SA, Mularoni L, MiguelEscalada I, Akerman I, Tena JJ, Moran I, Gomez-Marin C, van de Bunt M, et al. 2014 Pancreatic islet enhancer clusters enriched in type 2 diabetes risk-associated variants. Nature Genetics 46 136-143. (https://doi.org/10.1038/ng.2870)
(C) 2019 Society for Endocrinology Published by Bioscientifica Ltd. Printed in Great Britain 
Perrone S, Zubeldia-Brenner L, Gazza E, Demarchi G, Baccarini L, Baricalla A, Mertens F, Luque G, Vankelecom H, Berner S, et al. 2017 Notch system is differentially expressed and activated in pituitary adenomas of distinct histotype, tumor cell lines and normal pituitaries. Oncotarget 8 57072-57088. (https://doi.org/10.18632/ oncotarget.19046)

Quinlan AR \& Hall IM 2010 BEDTools: a flexible suite of utilities for comparing genomic features. Bioinformatics 26 841-842. (https://doi. org/10.1093/bioinformatics/btq033)

Radtke F \& Raj K 2003 The role of Notch in tumorigenesis: oncogene or tumour suppressor? Nature Reviews. Cancer 3 756-767. (https://doi org/10.1038/nrc1186)

Raetzman LT, Ross SA, Cook S, Dunwoodie SL, Camper SA \& Thomas PQ 2004 Developmental regulation of Notch signaling genes in the embryonic pituitary: Prop1 deficiency affects Notch2 expression. Developmental Biology 265 329-340. (https://doi.org/10.1016/j. ydbio.2003.09.033)

Raetzman LT, Wheeler BS, Ross SA, Thomas PQ \& Camper SA 2006 Persistent expression of Notch2 delays gonadotrope differentiation. Molecular Endocrinology 20 2898-2908. (https://doi.org/10.1210/ me.2005-0394)

Ranganathan P, Weaver KL \& Capobianco AJ 2011 Notch signalling in solid tumours: a little bit of everything but not all the time. Nature Reviews. Cancer 11 338-351. (https://doi.org/10.1038/nrc3035)

Rouault JP, Falette N, Guehenneux F, Guillot C, Rimokh R, Wang Q, Berthet C, Moyret-Lalle C, Savatier P, Pain B, et al. 1996 Identification of BTG2, an antiproliferative p53-dependent component of the DNA damage cellular response pathway. Nature Genetics 14 482-486. (https://doi.org/10.1038/ng1296-482)

Sjolund J, Johansson M, Manna S, Norin C, Pietras A, Beckman S, Nilsson E, Ljungberg B \& Axelson H 2008 Suppression of renal cell carcinoma growth by inhibition of Notch signaling in vitro and in vivo. Journal of Clinical Investigation 118 217-228. (https://doi. org/10.1172/JCI32086)

Tabuchi Y, Kitamura T, Fukuhara A, Mukai K, Onodera T, Miyata Y, Hamasaki T, Oshino S, Saitoh Y, Morii E, et al. 2016 Nur77 gene expression levels were involved in different ACTH-secretion autonomy between Cushing's disease and subclinical Cushing's disease. Endocrine Journal 63 545-554. (https://doi.org/10.1507/ endocrj.EJ15-0695)

Tando Y, Fujiwara K, Yashiro T \& Kikuchi M 2013 Localization of Notch signaling molecules and their effect on cellular proliferation in adult rat pituitary. Cell and Tissue Research 351 511-519. (https://doi. org/10.1007/s00441-012-1532-3)

Terra R, Luo H, Qiao X \& Wu J 2008 Tissue-specific expression of B-cell translocation gene 2 (BTG2) and its function in T-cell immune responses in a transgenic mouse model. International Immunology 20 317-326. (https://doi.org/10.1093/intimm/dxm152)
Touma W, Hoostal S, Peterson RA, Wiernik A, SantaCruz KS \& Lou E 2017 Successful treatment of pituitary carcinoma with concurrent radiation, temozolomide, and bevacizumab after resection. Journal of Clinical Neuroscience 41 75-77. (https://doi.org/10.1016/j. jocn.2017.02.052)

Trapnell C, Pachter L \& Salzberg SL 2009 TopHat: discovering splice junctions with RNA-Seq. Bioinformatics 25 1105-1111. (https://doi. org/10.1093/bioinformatics/btp120)

Trapnell C, Roberts A, Goff L, Pertea G, Kim D, Kelley DR, Pimentel H, Salzberg SL, Rinn JL \& Pachter L 2012 Differential gene and transcript expression analysis of RNA-seq experiments with TopHat and Cufflinks. Nature Protocols 7 562-578. (https://doi.org/10.1038/ nprot.2012.016)

Vela J, Perez-Millan MI, Becu-Villalobos D \& Diaz-Torga G 2007 Different kinases regulate activation of voltage-dependent calcium channels by depolarization in GH3 cells. American Journal of Physiology. Cell Physiology 293 C951-C959. (https://doi.org/10.1152/ ajpcell.00429.2006)

Wang J, Wakeman TP, Lathia JD, Hjelmeland AB, Wang XF, White RR, Rich JN \& Sullenger BA 2010 Notch promotes radioresistance of glioma stem cells. Stem Cells 28 17-28. (https://doi.org/10.1002/stem.261)

Wang Z, Li Y, Ahmad A, Banerjee S, Azmi AS, Kong D, Wojewoda C, Miele L \& Sarkar FH 2011 Down-regulation of Notch-1 is associated with Akt and FoxM1 in inducing cell growth inhibition and apoptosis in prostate cancer cells. Journal of Cellular Biochemistry 112 78-88. (https://doi.org/10.1002/jcb.25587)

Wenzl K, Troppan K, Neumeister P \& Deutsch AJ 2015 The nuclear orphan receptor NR4A1 and NR4A3 as tumor suppressors in hematologic neoplasms. Current Drug Targets 16 38-46. (https://doi. org/10.2174/1389450115666141120112818)

Xu Q, Yuan X, Tunici P, Liu G, Fan X, Xu M, Hu J, Hwang JY, Farkas DL, Black KL, et al. 2009 Isolation of tumour stem-like cells from benign tumours. British Journal of Cancer 101 303-311. (https://doi. org/10.1038/sj.bjc.6605142)

Zeng Q, Li S, Chepeha DB, Giordano TJ, Li J, Zhang H, Polverini PJ, Nor J, Kitajewski J \& Wang CY 2005 Crosstalk between tumor and endothelial cells promotes tumor angiogenesis by MAPK activation of Notch signaling. Cancer Cell 8 13-23. (https://doi.org/10.1016/j. ccr.2005.06.004)

Zhang Y, Liu T, Meyer CA, Eeckhoute J, Johnson DS, Bernstein BE, Nusbaum C, Myers RM, Brown M, Li W, et al. 2008 Model-based analysis of ChIP-Seq (MACS). Genome Biology 9 R137. (https://doi. org/10.1186/gb-2008-9-9-r137)

Zukeran A, Takahashi A, Takaoka S, Mohamed HM, Suzuki T, Ikematsu S \& Yamamoto T 2016 The CCR4-NOT deadenylase activity contributes to generation of induced pluripotent stem cells. Biochemical and Biophysical Research Communications 474 233-239. (https://doi.org/10.1016/j.bbrc.2016.03.119)

Received in final form 24 July 2018

Accepted 8 August 2018

Accepted Preprint published online 18 August 2018 (c) 2019 Society for Endocrinology Published by Bioscientifica Ltd. Printed in Great Britain 